\title{
Patterns of Use, Cessation Behavior and Socio-Demographic Factors Associated with Smoking in Saudi Arabia: a Cross- Sectional Multi-Step Study
}

\author{
Siddig Ibarhim Abdelwahab ${ }^{1 *}$, Maged El-Setohy ${ }^{1}$, Abdalla Alsharqi ${ }^{2}$, Rashad \\ Elsanosy $^{1}$, Umar Yagoub Mohammed $^{3}$
}

\begin{abstract}
Smoking is accountable for the fatality of a substantial number of persons and increases the likelihood of cancer and cardiovascular diseases. Although data have shown high prevalence rates of cigarette smoking in Saudi Arabia, relatively little is known about the broader scope. The objectives of this study were to investigate socio-demographic factors, patterns of use and cessation behavior associated with smoking in Saudi Arabia (KSA). The study utilized a cross-sectional, multi-step design of sampling. Residents ( $N=1,497$; aged 15 years and older) were recruited from seven administrative areas in Southwest Saudi Arabia. A pretested questionnaire was utilized to obtain data on participant cigarette smoking, including their daily use, age, education, income, marital status and employment status. The current study is the first of its kind to gather data cessation behavior of Saudi subjects. With the exception of $1.5 \%$ females, all the respondents were male. The majority of the respondents were married, had a university level of education, were employed, and were younger than 34 years old. The same trends were also observed among smokers' samples. The current prevalence of cigarette smoking was $49.2 \%$ and $65.7 \%$ of smokers had smoking at less than 18 years of age. The mean daily use amongst smokers was 7.98 cigarettes $(\mathrm{SD}=4.587)$. More than $50 \%$ of the study sample had tried at least once to quit smoking. However, $42 \%$ of the smokers participating had never. On the other hand, about $25 \%$ of the respondents were willing to consider quitting smoking in the future. Modeling of cigarette smoking suggested that the most significant independent predictors of smoking behavior were geographic area, gender, marital status, education, job and age. Considerable variation in smoking prevalence was noted related with participant sociodemographics. Findings recommend the necessity for control and intervention programs in Saudi community.
\end{abstract}

Keywords: Smoking - cigarette - demography - cessation - Saudi Arabia

Asian Pac J Cancer Prev, 17 (2), 655-660

\section{Introduction}

The increase of tobacco use is an exhausting mania for those involved in health care. Tobacco use resulted globally in one hundred million fatalities throughout the last century, and statistical reports point to the prospect of the estimated raise in the statistics of fatalities. This is approximate to be more than $75 \%$ of all drug and chemicals associated death (Fiore and Baker, 2009; Stewart et al., 2009; Glynn et al., 2010). Chemical compounds in tobacco estimated to be over 4000 and many of these hazardous agents are toxic and tumorgenic (Pera, 2003; Shevchenko, 2012). Nicotine is the chemical agent of cigarette smoking that responsible for its addictive properties but is not the main constituent related with disease caused by smoking. (Schmeltz and Hoffmann, 1977; Shihadeh and Saleh, 2005). Smoking is also the predisposing agent responsible for the furthest danger of sickness (loss of health and premature mortality) in the world (La Greca and Mackey, 2009). About 50\% of regular smokers dies of a smoking associated illnesses (Jha, 2009). More than 25 diseases are known to be associated with tobacco use, including pulmonary diseases and cancers and cardiovascular problems. Management of post-surgical wound is much complicated in smokers (Guo and DiPietro, 2010). The unfavorable side-effects of tobacco smoking are reversible, with cardiovascular risk declining considerably within the initial two years of smoking quitting (Gratziou, 2009).

Even though KSA is not a tobacco or cigarettes manufacturing country, cigarette smoking has existed in this kingdom for more than half decade. Import of manufactured cigarette has amplified noticeably with a cost of more than half billion Saudi Riyals (1Riyal=

${ }^{1}$ Substance Abuse Research Center (SARC), Jazan University, Jazan, ${ }^{2}$ Specialized Psychiatry Clinics, Riyadh, ${ }^{3}$ Department of Family and Community Medicine, Medical Services Department, Ministry of Defense, Riyadh, Saudi Arabia *For correspondence: siddigroa@yahoo.com 
3.76USD). Moreover, the health, public, religious and financial troubles of tobacco use, has an expenditure of more than four billion Riyals (1Riyal=3.76USD) nearly per year. Where the anticipated cost-effective burden of KSA due to premature deaths and productivity wastes due to tobacco from (1961-2004) more than 75 billion Riyals, as well as considerable number of premature fatalities cases due to ailment due to smoking as, lung and renal cancer, and heart diseases (Jarallah et al., 1999). Publications for the International Bank suggested that, nations and governments with high income pay yearly between 6-15\% from the healthcare overall expenditure to treat illnesses caused by smoking. Tobacco Control programs aim to reduce the health and financial burden related with smoking (AL-Doghether, 2004; Bassiony, 2009a).

No countrywide researches on tobacco smoking have been conducted in KSA. Few studies have demonstrated a variable smoking prevalence of between $8 \%$ and $57 \%$; the minority of these, however, was based on the whole community sampling. A family-based survey to investigate the prevalence and factors associated with cigarette smoking, utilizing national survey data of metabolic syndromes from three regions of KSA (AL-Doghether, 2004; Bassiony, 2009a). The percentage of cigarette smokers in KSA, on the base of a number of researches, approximately (35 to 45\%) among males (more than 15 years old), and (24\%) among schools' students (less than 15 years old). To this end, using a cross-sectional study design, the main rationale of this current research was to study cigarette smoking patterns in Saudi residents living in Jazan, the Southern region of the Kingdom. A second purpose of the study was to evaluate sociodemographic associates of cigarette smoking and the cessation behaviors of smokers as well.

\section{Materials and Methods}

\section{The study's geographic area}

The study's geographic area covered seven major administrative areas (Al-Towal, Samtah, Al-shamhanyeh, Al-Garadyeh, Al-Khograh, Al-Moasem and Ahd AlMasarhah) in Southwest region in Saudi Arabia. Jazan region extend to cover some $300 \mathrm{~km}$ along the southern Red Sea coastline. It covers a region of $11,672 \mathrm{~km}^{2}$ with a population of $1,365,110$. The principal city is Jazan. The choice to decide on these seven administrative areas as the study sampling outline was stood on the reality that these areas enclosed a variety of population bulk that permitted us to detain distinction in smoking prevalence within and between areas.

\section{Sampling technique and data collection}

This is a cross-sectional design of study, which recruited three stages organized sampling process to engage participants $(\mathrm{N}=1497)$. Firstly, seven administrative areas of Jazan region stated earlier were chosen based on previous justification. Secondly, from these areas, some public health care (PHC) centers within each area were sampled. Thirdly, Saudi citizens seeking health services from these PHC centers were randomly interviewed. Participants who were qualified to partake in the interview were aged 15 years or older. Data was collected by three trained health professionals. Upon getting survey explanations clarified by the research assistants, respondents were requested to fill out the study questionnaire which lasted about 25 minutes. Each respondent was allowed to ask any questions concerning research or questionnaire items and sufficient time to fill in the questionnaire. The Ethics Committee of the Substance Abuse Research Centre, Jazan University accepted the study and a printed informed consent were attained from each respondent. At the beginning of the study, a pilot study was conducted for some participants and some of the questionnaire's items were then rephrased and customized accordingly. Data from pilot study were not included in the final study. A smoker in this research was considered one who ever smoked and continues to smoke, even occasionally, but who does not depict himself as a past smoker. Exclusion criteria include people who are non-Arabic speakers, less than 15 years old and Sheesha smokers. The low response rate of females also mirrors the common unwillingness of Saudi women to contribute in studies of this kind.

\section{Measures}

The objective of this project was to investigate the socio-demographic factors, patterns of use and cessation behavior associated with cigarette smoking. To achieve this objectives some relevant measures (sociodemographic factors, patterns of use \& cessation behavior) were conventionally used due to their psychometric properties and previous use in many researches. These measures included geographic area, gender, marital status, education, income, job and age. Respondents were also questioned about their starting age of smoking, frequency of smoking, daily smoking, number of cigarettes smoked per day, reasons for smoking and easiness of getting the cigarettes. On the other hand smokers were asked about smoking previous and future quitting trails. To smear this research with potential prevention opportunities, participants were also asked about their perception of the most successful cessation program. All these items were designed in a questionnaire of 24 items.

\section{Statistical Analysis}

The collected data were validated and processed using SPSS20.0 software (IBM, NY, USA). A bivariate analysis was performed using Chi-squared tests with smoking status as the dependent variable and geographic area, gender, marital status, education, income, job and age as independent variables. A logistic regression was used to model and predict smoking. Smoking status as a dependent variable was coded as 0 for non-smokers and 1 for smokers. 2-tailed probabilities values of 0.05 or less were taken as statistical threshold of significance. Descriptive statistics were conducted utilizing percentages and means.

\section{Results}

A total of 1497 respondents participated in this study. 
The response rate was $99.8 \%$. The sociodemographic uniqueness of the sample is depicted in Table 1. With the exception of $10.6 \%$ female, all the respondents were male. The majority of the respondents was married, had a university level of education, was employed, was younger than 34 years old and was living in Samtah Area (Table 1). This trend was also observed among smokers' samples (Table 1).

The current prevalence of cigarette smoking was observed to be $49.2 \%$. Table 2 depicted smoking behaviors of 736 smokers. The average age of smoking initial start was 17.85 years $(\mathrm{SD}=4.075)$. The mean use per day amongst smokers was 7.98 cigarettes $(\mathrm{SD}=4.587)$. Over 29 percent $(n=218)$ of smoker participants report smoking of more than 10 cigarettes on daily basis. Most of the respondents were influenced by their life tensions and

Table 1. Sociodemographic Characteristics of the Study Sample (N=1497)

\begin{tabular}{|c|c|c|c|c|}
\hline \multirow{2}{*}{$\frac{\text { Variable }}{\text { Geographic area }}$} & \multirow[t]{2}{*}{$\mathrm{N}$} & \multirow[t]{2}{*}{$\%$ of total } & \multicolumn{2}{|c|}{ Smokers } \\
\hline & & & $\mathrm{n}$ & $\%$ \\
\hline Al-Towal & 272 & 18.6 & 113 & 15.4 \\
\hline Samtah & 494 & 33.7 & 242 & 33.1 \\
\hline Al-shamhanyeh & 30 & 2 & 10 & 1.4 \\
\hline Al-Garadyeh & 21 & 1.4 & 6 & 0.8 \\
\hline Al-Khograh & 144 & 9.8 & 59 & 8.1 \\
\hline Al-Moasem & 249 & 17 & 97 & 13.3 \\
\hline \multirow[t]{2}{*}{ Ahd Al-Masarhah } & 256 & 17.5 & 205 & 28 \\
\hline & \multicolumn{4}{|c|}{$\chi^{2}=766.95, \mathrm{df}=6, \mathrm{P}<.001$} \\
\hline \multicolumn{5}{|l|}{ Gender } \\
\hline Male & 1338 & 89.4 & 725 & 98.5 \\
\hline \multirow[t]{2}{*}{ Female } & 159 & 10.6 & 11 & 1.5 \\
\hline & \multicolumn{4}{|c|}{$\chi^{2}=928.55, \mathrm{df}=1, \mathrm{P}<.001$} \\
\hline \multicolumn{5}{|l|}{ Marital status } \\
\hline Single & 649 & 43.4 & 300 & 40.8 \\
\hline Married & 730 & 48.8 & 390 & 53 \\
\hline \multirow{2}{*}{ Divorced/ widowed } & 118 & 7.9 & 46 & 6.3 \\
\hline & \multicolumn{4}{|c|}{$\chi^{2}=442.9, \mathrm{df}=2, \mathrm{P}<.001$} \\
\hline \multicolumn{5}{|l|}{ Education } \\
\hline University & 634 & 42.4 & 339 & 46.1 \\
\hline Postgraduate & 28 & 1.9 & 15 & 2 \\
\hline High Secondary & 645 & 43.1 & 299 & 40.6 \\
\hline Elementary Schools & 143 & 9.6 & 69 & 9.4 \\
\hline \multirow[t]{2}{*}{ Uneducated } & 47 & 3.1 & 14 & 1.9 \\
\hline & \multicolumn{4}{|c|}{$\chi^{2}=1313.36, \mathrm{df}=4, \mathrm{P}<.001$} \\
\hline \multicolumn{5}{|l|}{ Income (SAR*) } \\
\hline $0-2500$ & 229 & 21 & 92 & 16.1 \\
\hline 2501 - $5000 \mathrm{SAR}$ & 543 & 49.8 & 287 & 50.1 \\
\hline 5001 - 7500 SAR & 247 & 22.6 & 136 & 23.7 \\
\hline \multirow{2}{*}{ More than 7500 SAR } & 72 & 6.6 & 58 & 10.1 \\
\hline & \multicolumn{4}{|c|}{$\chi^{2}=424.97, \mathrm{df}=3, \mathrm{P}<.001$} \\
\hline Mean (Income) \pm SD & 4397.1 & \pm 2341.492 & (SAF & \\
\hline \multicolumn{5}{|l|}{ Job } \\
\hline Yes & 1007 & 67.3 & 551 & 74.9 \\
\hline \multirow[t]{2}{*}{ No } & 490 & 32.7 & 185 & 25.1 \\
\hline & \multicolumn{4}{|c|}{$\chi^{2}=178.55, \mathrm{df}=1, \mathrm{P}<.001$} \\
\hline \multicolumn{5}{|l|}{ Age (years) } \\
\hline less than 25 & 321 & 21.4 & 114 & 15.5 \\
\hline $25-34$ & 728 & 48.6 & 375 & 51 \\
\hline $35-44$ & 330 & 22 & 196 & 26.6 \\
\hline \multirow[t]{2}{*}{ More than 44} & 118 & 7.9 & 51 & 6.9 \\
\hline & \multicolumn{4}{|c|}{$\chi^{2}=522.63, \mathrm{df}=3, \mathrm{P}<.001$} \\
\hline Mean (Age) \pm SD & 30.8 & $\pm 8.974(Y$ & ears) & \\
\hline
\end{tabular}

*US1 = SAR3.76 peers to start smoking.

Table 3 shows smoking cessation behavior among the study sample $(\mathrm{N}=736)$. More than $50 \%$ of the study sample has tried at least once to quit smoking. However, $42 \%$ of the smokers participated in this study have never tried before to quit smoking. On the other hand, about $25 \%$ of the respondents were willing to quit smoking in the future. Although smokers are aware of the available smoking cessation programs, their perception of the most successful cessation program was studied in this research. $88.6 \%$ of the respondents felt that school awareness programs are potentially successful (Table 3).

A preliminary univariate analysis (Table 1) was conducted to identify potential risk factors, [age, gender, education level, marital status, residence and occupation], followed by binomial multivariate logistic regression analysis (Table 4). Modeling of cigarette smoking, was based on current smoking as dependent variable ( 0 for non-smoker and 1 for smoker), suggesting that the most

Table 2. Smoking behavior among the study sample $(\mathrm{N}=736)$

\begin{tabular}{|c|c|c|}
\hline Variables & Total N & Percentage \\
\hline \multicolumn{3}{|l|}{ Starting Age (Years) } \\
\hline$<18$ & 482 & 65.7 \\
\hline $18-20$ & 121 & 16.5 \\
\hline$\geq 21$ & 131 & 17.8 \\
\hline \multicolumn{3}{|l|}{ Smoking status } \\
\hline Yes & 736 & 49.2 \\
\hline No & 731 & 50.8 \\
\hline \multicolumn{3}{|l|}{ Daily smoking } \\
\hline Yes & 635 & 86.3 \\
\hline No & 101 & 13.7 \\
\hline \multicolumn{3}{|l|}{ Frequency of smoking } \\
\hline Once a day & 26 & 3.5 \\
\hline Two to three time a day & 235 & 31.9 \\
\hline Frequently/day & 343 & 46.6 \\
\hline Two to three time a week & 81 & 11 \\
\hline Irregular smoker & 51 & 6.9 \\
\hline \multicolumn{3}{|c|}{ Number smoked per day (cigarettes) } \\
\hline$<10$ & 518 & 70.4 \\
\hline 19-Oct & 153 & 20.8 \\
\hline 20 or more & 65 & 8.8 \\
\hline \multicolumn{3}{|l|}{ Reasons for smoking (Yes \%) } \\
\hline For entertainment & 535 & 72.7 \\
\hline Because of my friend smoke & 232 & 31.5 \\
\hline Because of my parents smoke & 550 & 74.7 \\
\hline pressure & 628 & 85.3 \\
\hline \multicolumn{3}{|l|}{ Easiness of getting the cigarettes } \\
\hline Very Easy & 528 & 71.7 \\
\hline Easy & 172 & 23.4 \\
\hline Difficult & 35 & 4.8 \\
\hline Impossible & 1 & 0.1 \\
\hline \multicolumn{3}{|l|}{ How do you get the cigarettes } \\
\hline By buying it & 555 & 75.4 \\
\hline share it with friends & 151 & 20.5 \\
\hline Getting it from my parents & 27 & 3.7 \\
\hline Others & 3 & 0.4 \\
\hline \multicolumn{3}{|c|}{ How many of your friends are smokers } \\
\hline None of them & 34 & 4.6 \\
\hline Few of them & 220 & 29.9 \\
\hline Most of them & 318 & 43.2 \\
\hline All of them & 164 & 22.3 \\
\hline
\end{tabular}


Table 3. Smoking cessation behavior among the study sample $(\mathbf{N}=736)$

\begin{tabular}{lcc}
\hline Variables & Total N & Percentage \\
\hline Have you ever tried to quit smoking? & & \\
Yes & 417 & 56.8 \\
No & 317 & 43.2 \\
Number of cessation trails (times) & & \\
0 & 315 & 42.8 \\
1 & 71 & 9.6 \\
2 & 171 & 23.2 \\
3 & 86 & 11.7 \\
4 & 32 & 4.3 \\
More Than 4 & 61 & 8.3 \\
Will you quit smoking in the future & & \\
Surely Yes & 182 & 24.8 \\
Surely No & 101 & 13.8 \\
Possibly Yes & 326 & 44.4 \\
I don't think so & 125 & 17 \\
Perception on the most successful cessation program (Yes) \\
School awareness program & 650 & 88.6 \\
Nicotine mixed gum (NRT) & 521 & 70.9 \\
TV & 577 & 78.5 \\
Radio & 547 & 74.4 \\
Others & 73 & 9.9 \\
\hline
\end{tabular}

significant independent predictors of smoking behavior were geographic area, gender, marital status, education, job and age. Results showed that respondents living in the Ahd Al-Masarhah were more aptly to smoke than those living in Al-Towal $(\mathrm{OR}=4.426$, 95\% C.I $=2.638$ -7.425). Similarly, people who were unmarried were 2.0 more likely to smoke than those who were divorced/ widowed, after controlling for additional variables in the model. Therefore, the odds of being smoker for unemployed respondents compared to working people will be decreased by a factor of 0.42 (95.0\% C.I. for OR is 0.235 to 0.749 ), after controlling for additional variables in the model.

\section{Discussion}

The current paper was designed to investigate the demography, patterns of use and cessation behavior associated with smoking in the selected seven administrative areas of Jazan region. The current prevalence of cigarette smoking was observed to be $49.2 \%$. A previous study conducted in Saudi Arabia showed that prevalence of cigarette smoking among Saudi male graduate students was 21.6\% (Al-Mohamed and Amin, 2010). However, the prevalence of different types of smoking (cigarette and waterpipe) was reported to be from 2.4-52.3\% (Bassiony, 2009b). Varying smoking prevalence rates have been reported for developing and developed countries (Saeed et al., 1996).

The prevalence of smoking in males is $54.2 \%(\mathrm{n}=725)$, while in females is $6.9 \%(\mathrm{n}=11)$. The general pattern of lesser smoking prevalence and minor daily cigarette use among women is reported for almost all developing societies. This may be connected to social, religious and cultural factors, and the economic dependence of women on men. However, smoking surveys among women in developing countries and Arab and Moslem communities
Table 4. Modeling of smoking behavior using logistic regression (SLR)

\begin{tabular}{|c|c|c|c|c|c|}
\hline \multirow[t]{2}{*}{ Variables } & \multirow[t]{2}{*}{$\beta$} & \multirow[t]{2}{*}{$\mathrm{P}$} & \multirow[t]{2}{*}{$\begin{array}{l}\text { Odd } \\
\text { ratio }\end{array}$} & \multicolumn{2}{|c|}{$\begin{array}{c}95.0 \% \\
\text { C.I. for OR }\end{array}$} \\
\hline & & & & Lower & Upper \\
\hline \multicolumn{6}{|l|}{ Geographic area } \\
\hline Al-Towal & & 0 & 1 & & \\
\hline Samtah & -0.027 & 0.89 & 0.973 & 0.66 & 1.433 \\
\hline Al-shamhanyeh & -0.714 & 0.11 & 0.489 & 0.204 & 1.175 \\
\hline Al-Garadyeh & -0.66 & 0.221 & 0.517 & 0.179 & 1.488 \\
\hline Al-Khograh & -0.209 & 0.411 & 0.811 & 0.492 & 1.336 \\
\hline Al-Moasem & 0 & 0.999 & 1 & 0.651 & 1.536 \\
\hline Ahd Al-Masarhah & 1.488 & 0 & 4.426 & 2.638 & 7.425 \\
\hline \multicolumn{6}{|l|}{ Gender } \\
\hline Male & & & 1 & & \\
\hline Female & -2.725 & 0 & 0.066 & 0.031 & 0.139 \\
\hline \multicolumn{6}{|l|}{ Marital status } \\
\hline Single & & 0.008 & 1 & & \\
\hline Married & 0.066 & 0.669 & 1.069 & 0.788 & 1.449 \\
\hline Divorced/ widowed & -0.692 & 0.009 & 0.501 & 0.298 & 0.842 \\
\hline \multicolumn{6}{|l|}{ Education } \\
\hline University & & 0.145 & 1 & & \\
\hline Postgraduate & -0.293 & 0.523 & 0.746 & 0.304 & 1.834 \\
\hline High Secondary & -0.054 & 0.748 & 0.947 & 0.68 & 1.319 \\
\hline Elementary Schools & -0.274 & 0.282 & 0.761 & 0.462 & 1.252 \\
\hline Uneducated & -1.22 & 0.013 & 0.295 & 0.113 & 0.771 \\
\hline \multicolumn{6}{|l|}{ Job } \\
\hline \multicolumn{6}{|l|}{ Yes } \\
\hline No & -0.868 & 0.003 & 0.42 & 0.235 & 0.749 \\
\hline \multicolumn{6}{|l|}{ Income (SAR*) } \\
\hline $0-2500$ & & 0.117 & 1 & & \\
\hline 2501 - $5000 \mathrm{SAR}$ & 0.015 & 0.94 & 1.016 & 0.679 & 1.52 \\
\hline $5001-7500 \mathrm{SAR}$ & -0.357 & 0.163 & 0.7 & 0.423 & 1.156 \\
\hline More than 7500 SAR & 0.334 & 0.425 & 1.397 & 0.614 & 3.179 \\
\hline Age (years) & 0.024 & 0.036 & 1.024 & 1.002 & 1.047 \\
\hline Constant & -0.389 & 0.353 & 0.678 & & \\
\hline
\end{tabular}

Dependent variable coding: $0=$ Non_Smoker $($ No); $1=$ Smoker (Yes); Hosmer and Lemeshow goodness of fit test $\chi^{2}=18.456$ $\mathrm{P}=0.018 ;-2$ Log likelihood ratio $=1239.235 ; \mathrm{B}$ : Regression coefficient

in particular may be less precise because some women may deny the practice where it is still socially undesirable. The low response rate of females also mirrors the common unwillingness of Saudi women to contribute in studies of this kind (Al-Sanosy, 2009; Vicknasingam et al., 2010). Such low prevalence of smoking women was also reported previously (Abed et al., 1988; Saeed et al., 1996).

Significantly higher smoking prevalence and daily cigarette consumption were reported earlier to be associated with high level of education (Nagelhout et al., 2012). In our study, we found that more than $46 \%$ of the smokers are university graduates. Higher level of education may help policy makers and health educators to design appropriate smoking cessation campaign with acceptable rate of quitting success.

Among the positive aspects of this study was the finding that depicts the smoking cessation behavior. The majority of respondents plans to quit or had already tried to quit. This finding is a strong encouragement for policy makers and health educators to plan for smoking cessation programs. We have intensively reviewed cessation efforts in Muslim comminutes in our previously published review 
paper (Abdelwahab et al., 2013), and some conclusion of that review paper could be merged with the results of this paper to succeed in the fighting against smoking. On the other hand, the current study also investigated the perception of respondents on the most successful cessation program. Respondents have ranked the programs according to their experience and perception, with school awareness program on the top.

The results of the logistic regression model showed that geographic area, gender, marital status, education, job and age were the only significant variables in this model. The significant different effects of the different areas studied in this paper on the smoking behavior may be due some dissimilarities in standards of living and cultural values (Yang et al., 2008). Results indicated that participants living in the Ahd Al-Masarhah area were more likely to smoke than those living in Al-Towal $(\mathrm{OR}=4.426,95 \%$ C.I. $=2.638-7.425)$. Constant with previous results (Hong and Wang, 2007; Al Ghobain et al., 2011; Mahfouz et al., 2014), respondents age was another sociodemographic varaible that was associated with smoking, with the oldest age category being more likely to engage in smoking (Beta:0.024; SEM:0.011; P-value: 0.036). Also constant with the scientific literature (Broms et al., 2004; Yang et al., 2005) is the result that married people were more likely to smoke than single persons, a finding that is in dissimilarity to those that stated no variation by marital status (Unger et al., 2003; Yang et al., 2008).

The limitations of this cross-sectional research were the exclusion of seven governorates of Jazan regions for the sake of a uniform sociodemographic data and the lesser number of female participants to surmount some administrative and social difficulties related to including women in this study and limits its generalizability. Future studies are desirable to collect both longitudinal and crosssectional smoking survey statistics in all the regions of Saudi Arabia.

In conclusion, the current study is the first of its kind in discussing the smoking behavior and cessation in the general population regardless of taking special sector. A quick and well-planned control programs are highly required to counter the high prevalence of smoking. Unique data obtained on cessation behavior are a corner stone to target some specific sectors of the smokers.

\section{References}

Abdelwahab SI, Yagoub U, Al Sunosi R, et al (2013). Smoking cessation efforts in special population: a review of research on muslim countries and communities. Int J Pharmacol, 9.

Abed J, Al Dabbagh S, Khalil H, et al (1988). Cigarette smoking: epidemiology and effects on some cardiovascular parameters in medical students. Ann Coll Med Mosul, 14, 33-9.

AL-Doghether M (2004). Smoking cessation interventions; behavioural interventions. Middle East Journal of Family Med, 2, 1-10.

Al-Mohamed H, Amin T (2010). Pattern and prevalence of smoking among students at king faisal university, Al Hassa, Saudi Arabia. EMHJ, 16.

Al-Sanosy RM (2009). Pattern of khat abuse and academic performance among secondary school and college students in Jazan region, Kingdom of Saudi Arabia (KSA). J Family Community Med, 16, 89.

Al Ghobain MO, Al Moamary MS, Al Shehri SN, et al (2011). Prevalence and characteristics of cigarette smoking among 16 to 18 years old boys and girls in Saudi Arabia. Ann Thoracic Med, 6, 137.

Bassiony MM (2009a). Smoking in Saudi Arabia. Saudi Med J, 30, 876-81.Bassiony MM (2009b). Smoking in Saudi Arabia. Saudi Med J, 30, 876-81.

Broms U, Silventoinen K, Lahelma E, et al (2004). Smoking cessation by socioeconomic status and marital status: the contribution of smoking behavior and family background. Nicotine Tobacco Res, 6, 447-55.

Fiore MC, Baker TB (2009). Stealing a march in the 21st century: accelerating progress in the 100-year war against tobacco addiction in the United States. J Informat, 99.

Glynn T, Seffrin JR, Brawley OW, et al (2010). The globalization of tobacco use: 21 challenges for the 21 st century. CA Cancer $J$ Clin, 60, 50-61.

Gratziou C (2009). Respiratory, cardiovascular and other physiological consequences of smoking cessation. Current Med Res Opin, 25, 535-45.

Guo S, DiPietro LA (2010). Factors affecting wound healing. $J$ Dental Res, 89, 219-29.

Hong Q, Wang D (2007). Prevalence survey of smoking behavior and socioeconomic status among rural residents in Anhui province [J]. Chinese Rural Health Service Administrat, 2, 7.

Jarallah JS, Al-Rubeaan KA, Al-Nuaim ARA, et al (1999). Prevalence and determinants of smoking in three regions of Saudi Arabia. Tobacco Control, 8, 53-6.

Jha P (2009). Avoidable global cancer deaths and total deaths from smoking. Nature Rev Cancer, 9, 655-64.

La Greca AM, Mackey ER (2009). Type 1 Diabetes Mellitus, in: O’Donohue TW (Ed.), Behavioral Approaches to Chronic Disease in Adolescence: A Guide to Integrative Care. Springer New York, NY, 85-100.

Mahfouz MS, Alsanosy RM, Gaffar AM, et al (2014). Tobacco use among university students of Jazan region: gender differences and associated factors. BioMed Research International, 2014.

Nagelhout GE, de Korte-de Boer D, Kunst AE, et al (2012). Trends in socioeconomic inequalities in smoking prevalence, consumption, initiation, and cessation between 2001 and 2008 in the Netherlands. Findings from a national population survey. BMC Public Health, 12, 303.

Saeed A, Khoja TA, Khan SB (1996). Smoking behaviour and attitudes among adult Saudi nationals in Riyadh City, Saudi Arabia. Tobacco Control, 5, 215-9.

Schmeltz I, Hoffmann D (1977). Nitrogen-containing compounds in tobacco and tobacco smoke. Chem Rev, 77, 295-311.

Shevchenko V (2012). Characterization of chemical compounds in cigarette filters leachates. PhD Thesis. San Diego State University.

Shihadeh A, Saleh R (2005). Polycyclic aromatic hydrocarbons, carbon monoxide. Food Chemical Toxicol, 43, 655-61.

Stewart ST, Cutler DM, Rosen AB (2009). Forecasting the effects of obesity and smoking on US life expectancy. $N$ Engl $J$ Med, 361, 2252-60.

Unger JB, Shakib S, Boley Cruz T, et al (2003). Smoking behavior among urban and rural Native American adolescents in California. Am J Prev Med, 25, 251-4.

Vicknasingam B, Mazlan M, Schottenfeld R, et al (2010). Injection of buprenorphine and buprenorphine/naloxone tablets in Malaysia. Drug Alcohol Dependence, 111, 44-9.

Yang G, Ma J, Liu N, et al (2005). Smoking and passive smoking in Chinese, 2002. Zhonghua Liu Xing Bing Xue Za Zhi, 26, 77-83 (in Chinese). 
Siddig Ibarhim Abdelwahab et al

Yang T, Li F, Yang X, et al (2008). Smoking patterns and sociodemographic factors associated with tobacco use among Chinese rural male residents: a descriptive analysis. BMC Public Health, 8, 248. 